\title{
Mineralogia e geoquímica de sedimentos de manguezais da costa amazônica: o exemplo do estuário do rio Marapanim (Pará)
}

\author{
José Francisco Berrêdo ${ }^{1}$, Marcondes Lima da Costa ${ }^{2}$, Maria do Perpétuo Socorro Progene Vilhena ${ }^{3}$ \\ \& Josiana Torres dos Santos ${ }^{3}$
}

\begin{abstract}
Resumo Os manguezais do estado do Pará representam importante segmento da costa norte brasileira sobre os quais pouco se conhece das características geológicas e as relações com área(s)-fonte. A pesquisa foi realizada no estuário do rio Marapanim, na costa paraense, para demonstrar a contribuição de sedimentos continentais para a formação dos sedimentos dos manguezais. Foram coletados sedimentos da Formação Barreiras e solos dela derivados (principais fontes terrígenas), e os sedimentos de manguezal. Nos sedimentos de manguezal foram realizadas análises granulométricas, determinação dos teores de carbono $(\mathrm{C} \%)$ e medidas de $\mathrm{pH}$, Eh $\mathrm{e}$ salinidade intersticial. A determinação mineralógica e a geoquímica multi-elementar foi feita nos sedimentos lamosos e nos sedimentos continentais adjacentes, para comparações. Os sedimentos de manguezal são sílticoargilosos (> $90 \%$ ), com teores de carbono entre 0,75 a 3,5\%. A mineralogia principal é composta por quartzo, goethita, hematita, caulinita, illita, além de zircão, turmalina, estaurolita e cianita como acessórios, assinatura mineralógica típica dos sedimentos da Formação Barreiras e dos solos. De ocorrência comum nesses manguezais, os minerais neoformados são: esmectita, feldspato potássico, pirita, halita, gipso e a jarosita. O enriquecimento em $\mathrm{SiO}_{2}, \mathrm{Al}_{2} \mathrm{O}_{3}, \mathrm{Fe}_{2} \mathrm{O}_{3}, \mathrm{e} \mathrm{TiO}$ nos manguezais e os níveis crustais dos metais-traço refletem o clima tropical e a composição mineralógica da área-fonte, rica em quartzo e caulinita e a ausência de influência antrópica. A composição química associada à matéria orgânica, abundantes diatomáceas além de $\mathrm{Fe}, \mathrm{S}$ e os aportes de $\mathrm{Cl}^{-}$, $\mathrm{Na}^{+}, \mathrm{K}^{+}, \mathrm{Ca}^{++} \mathrm{e} \mathrm{Mg}^{++}$da água do mar, identificam o ambiente deposicional e os minerais autigênicos. O padrão de fracionamento dos elementos-traço nos manguezais também corrobora a marcante contribuição da áreafonte continental. Esses sedimentos apresentam o predomínio dos Elementos Terras Rara Leves (ETRL) sobre os Elementos Terras Raras Pesados (ETRP) com elevadas razões de Th/Co; La/Th; $\mathrm{La} / \mathrm{Sc} ; \mathrm{La} / \mathrm{Co}$ e Zr/Sc e Th/ $\mathrm{Sc}$ e $\mathrm{Ba} / \mathrm{Co}$, elementos presentes nas rochas ígneas félsicas que originaram os sedimentos terrígenos.
\end{abstract}

Palavras-chave: mineralogia de manguezais, costa norte, geoquimica, metais traço.

\begin{abstract}
Mineralogy and Geochemistry of Mangrove's Sediments of the Amazonian Coast: The Example of Marapanim River Estuary (Para State). The mangroves of the Para state represents an important segment of the Brazilian north coast on the ones which little it is known of the geological characteristics and it relationships with source areas. This research was accomplished in the Marapanim river estuary, in the Para coast, to demonstrate the contribution of continental sediments for the constititution of the mangrove's sediments. The mangrove's sediments and the Barreiras Formation sediments and soils (main continental sources) were collected. In the mangrove's sediments grain size, determination of the carbon $(\mathrm{C} \%), \mathrm{pH}$ and Eh measures and interstitial salinity was made. The mineralogical determination and the multi-elementary geochemistry was made in the sediments muddy and terrigenous adjacents sediments for comparisons. The mangrove's sediments are clayey silty (>90\%), with the carbon values among 0,75 to $3,5 \%$. The main mineralogy is composed by quartz, goethita, hematite, kaolinite, illite, besides zircon, tourmaline, staurolite and cianite as accessories, what indicates contribution of the Barreiras Formation sediments and sediments muddy. It is common the occurrence in these mangroves the neoformated minerals as: smectite, K-felspars, pyrite, halite, gipsum and jarosite. The enrichment in $\mathrm{SiO}_{2} \mathrm{Al}_{2} \mathrm{O}_{3}, \mathrm{Fe}_{2} \mathrm{O}_{3}$ and $\mathrm{TiO}_{2}$ in the mangroves and the low tenors in trace metals reflects the tropical climate and the mineralogical composition of the source area, enriched in quartz and caulinite, with low tenors in $\mathrm{K}_{2} \mathrm{O}, \mathrm{Na}_{2} \mathrm{O}, \mathrm{MgO}$ and $\mathrm{CaO}$. The chemical composition associated to the organic matter, abundant diatoms besides $\mathrm{Fe}, \mathrm{S}$ and the marine contributions of $\mathrm{Cl}^{-}, \mathrm{Na}^{+}, \mathrm{K}^{+}$, $\mathrm{Ca}^{++}$and $\mathrm{Mg}^{++}$, identify the deposicional ambient and the autigenics minerals. The concentrations and the geochemical behaviour of the trace metals in the mangroves corroborates the outstanding contribution of the continental source area. Those sediments presents the prevalence of the Light Rare Earth Elements (LREE) on the Heavy Rare Earth Elements (HREE) with high reasons of Th/Co; La/Th; $\mathrm{La} / \mathrm{Sc} ; \mathrm{La} / \mathrm{Co}$ and $\mathrm{Zr} / \mathrm{Sc}$ and Th/ $\mathrm{Sc}$ and $\mathrm{Ba} / \mathrm{Co}$, elements present in the felsic igneous rocks that originated the continental sediments.
\end{abstract}

Keywords: mangrove's mineralogy, north coast, geochemistry, trace metals.

1 - Coordenação de Ciências da Terra e Ecologia/Museu Paraense Emílio Goeldi, Belém (PA), Brasil. E-mail: berredo@museu-goeldi.br

2 - Centro de Geociências, Universidade Federal do Pará, Belém (PA), Brasil. E-mail: mlc@ufpa.br

3 - Centro de Geociências, Universidade Federal do Pará, Belém (PA), Brasil. E-mail: sprogene@ufpa.br; jtorresdossantos@yahoo.com.br 
INTRODUÇÃO As pesquisas realizadas nos manguezais brasileiros geralmente enfocam os processos biológicos ou biogeoquímicos envolvendo a flora e fauna, os estudos ecológicos, a modelagem e o manejo, com vários artigos científicos já publicados, cabendo a Schaeffer-Novelli (1986) e Kjerfve \& Lacerda (1993) a listagem de uma série de referências sobre os mais variados assuntos. O mesmo esforço, contudo, não tem sido empregado para o conhecimento das características geológicas desses ecossistemas, especialmente no que concerne aos aspectos geoquímicos e mineralógicos dos sedimentos lamosos.

As contribuições mineralógicas (aluminossilicatos e óxi-hidróxidos de ferro) transportadas em suspensão, os íons marinhos dissolvidos $\left(\mathrm{Na}^{+}, \mathrm{K}^{+}, \mathrm{Ca}^{++}\right.$ e $\mathrm{Mg}^{++}, \mathrm{SO}_{4}^{=}$) e o plâncton (diatomáceas), constituem a base para múltiplos e complexos processos biogeoquímicos que ocorrem na planície lamosa, através de reações da matéria orgânica com os íons sulfato e os produtos da degradação de minerais detríticos (Michalopoulos \& Aller (1995). Desta forma, a mineralogia primária controla a composição química dos sedimentos dos manguezais e a formação de novos minerais em meio redutor, associado à decomposição da matéria orgânica; esse é o caso da pirita $\left(\mathrm{FeS}_{2}\right)$, produto final dos processos de sulfato-redução, cuja formação depende da disponibilidade do ferro reativo ou do alumínio, no caso de aluminossilicatos formados a partir da sílica biogênica presente como diatomáceas nos sedimentos (Costa et al. op. cit, Berrêdo 2006).

Vale ressaltar que no litoral paraense os únicos trabalhos existentes sobre $\mathrm{o}$ assunto pertencem a Behling \& Costa (2004) e Costa et al. (2004), realizados na zona Bragantina (nordeste do Pará), distante aproximadamente $110 \mathrm{~km}$ do estuário do rio Marapanim. Neste artigo, dá-se continuidade às pesquisas anteriores, apresentando-se os dados sobre a composição mineralógica dos sedimentos dos manguezais, baseado na fração dos minerais leves, minerais pesados, argilominerais e na geoquímica multi-elementar, ferramenta bastante utilizada em estudos de proveniência (Martin et al. 1976. Yang et al. 2002, Borrego et al. 2005). Os resultados foram comparados com os sedimentos da Formação Barreiras e solos derivados, com o objetivo de avaliar a transferência dos sedimentos da principal área-fonte continental para os manguezais do estuário do rio Marapanim.

CARACTERÍSTICAS DA ÁREA DE ESTUDO O estuário do rio Marapanim está localizado na costa nordeste do estado do Pará, em um setor inteiramente preservado das atividades antrópicas situado a leste da desembocadura do rio Amazonas, limitado pelas coordenadas: $00^{\circ} 32^{\prime}$ $30^{\prime \prime} \mathrm{S} / 00^{\circ} 52^{\prime} 30^{\prime \prime} \mathrm{S}$ e $47^{\circ} 28^{\prime} 45^{\prime}$ ' W / 4 $7^{\circ} 45^{\prime} 00^{\prime \prime} \mathrm{W}$ (Fig. 1). O clima é o tropical chuvoso (até $3000 \mathrm{~mm}$ anuais), quente (média de $27,7^{\circ} \mathrm{C}$ ) e úmido (umidade entre 80 e 85 $\%$ ), sujeito a macromarés semidiurnas (até $5 \mathrm{~m}$ ).

A região é influenciada pela Zona Intertropical de Convergência que determina as maiores quantidades de chuva entre os meses de janeiro a junho e as menores precipitações entre julho a dezembro (AGÊNCIA
DE DESENVOLVIMENTO DA AMAZÔNIA inédito). Como conseqüência, o rio Marapanim é altamente sazonal, contribuindo com grande quantidade de sedimentos e água doce durante os períodos mais chuvosos. $\mathrm{Na}$ estiagem, a salinidade mais alta das águas superficiais é de 35 na foz, diminuindo sensivelmente rio acima (Berrêdo 2006).

Os sedimentos da formação Barreiras (Terciário), de grande expressão na região e os depósitos holocênicos (quaternários), são as principais unidades geológicas da área. Os sedimentos quaternários também ocupam grandes áreas, representados por praias, dunas e paleodunas, pântanos salinos, planícies de maré, planície de maré lamosa, barras arenosas e lamosas, além dos depósitos aluviais (Silva 1998).

$\mathrm{O}$ estuário do rio Marapanim situa-se em uma costa entrecortada formada por vales parcialmente submersos durante o Holoceno (Barbosa \& Pinto 1973), característica do litoral paraense, cuja configuração atual associa-se a movimentos tectônicos, controlada por falhamentos (Borges et al. 1995). Foi subdividido por Silva (1998) em quatro domínios geomorfológicos: planalto costeiro, planície costeira, planície estuarina e planície aluvial. Para os objetivos da pesquisa destaca-se o planalto costeiro, o qual abriga as falésias da Formação Barreiras e a planície estuarina, sobre a qual se instalaram os manguezais, colonizando os depósitos arenosos e lamosos.

A cobertura vegetal é constituída pela vegetação de capoeira (Góes Filho et al. 1973), que se desenvolveu sobre os Latossolos. As formações vegetais pioneiras são representativas dos terrenos quaternários e encontram-se em íntima associação com as feições morfoestratigráficas dos diferentes ambientes deposicionais (Silva 1998). São constituídas por manguezais, principalmente bosques mistos de Rhyzophora mangle e Avicennia germinans, restingas e campos naturais (Prost et al. 2001), ocupando os depósitos sedimentares resultantes de processos estuarinos ou marinhos.

MATERIAIS E MÉTODOS Os sedimentos da Formação Barreiras foram coletados ao longo do estuário do rio Marapanim. Os sedimentos de manguezal foram coletados em dois setores do estuário (Fig. 1), em transectos previamente nivelados topograficamente (Berrêdo 2006). Esses setores caracterizam-se pela maior ou menor influência das águas oceânicas: no setor A, a salinidade intersticial máxima atinge $44 \mathrm{e}$, no setor B, com salinidade em torno de 28 , influenciado pelo aporte de águas do rio;

As coletas de sedimento de manguezal foram realizadas em maré baixa, com testemunhador metálico semicilíndrico de $3 \mathrm{~cm}$ de diâmetro. Foram feitas medições físico-químicas (pH, Eh e salinidade intersticial), até 3 horas após as coletas, em laboratório de campo. Os testemunhos foram subdivididos em 0-5 cm, 5-10 $\mathrm{cm}, 10-20 \mathrm{~cm}$, a partir daí, em intervalos de $20 \mathrm{~cm}$ até a profundidade de $2 \mathrm{~m}$. Nos intervalos selecionados foi medida a salinidade intersticial, com um refratômetro de campo (ATAGO), mediante a extração, sob pressão, 


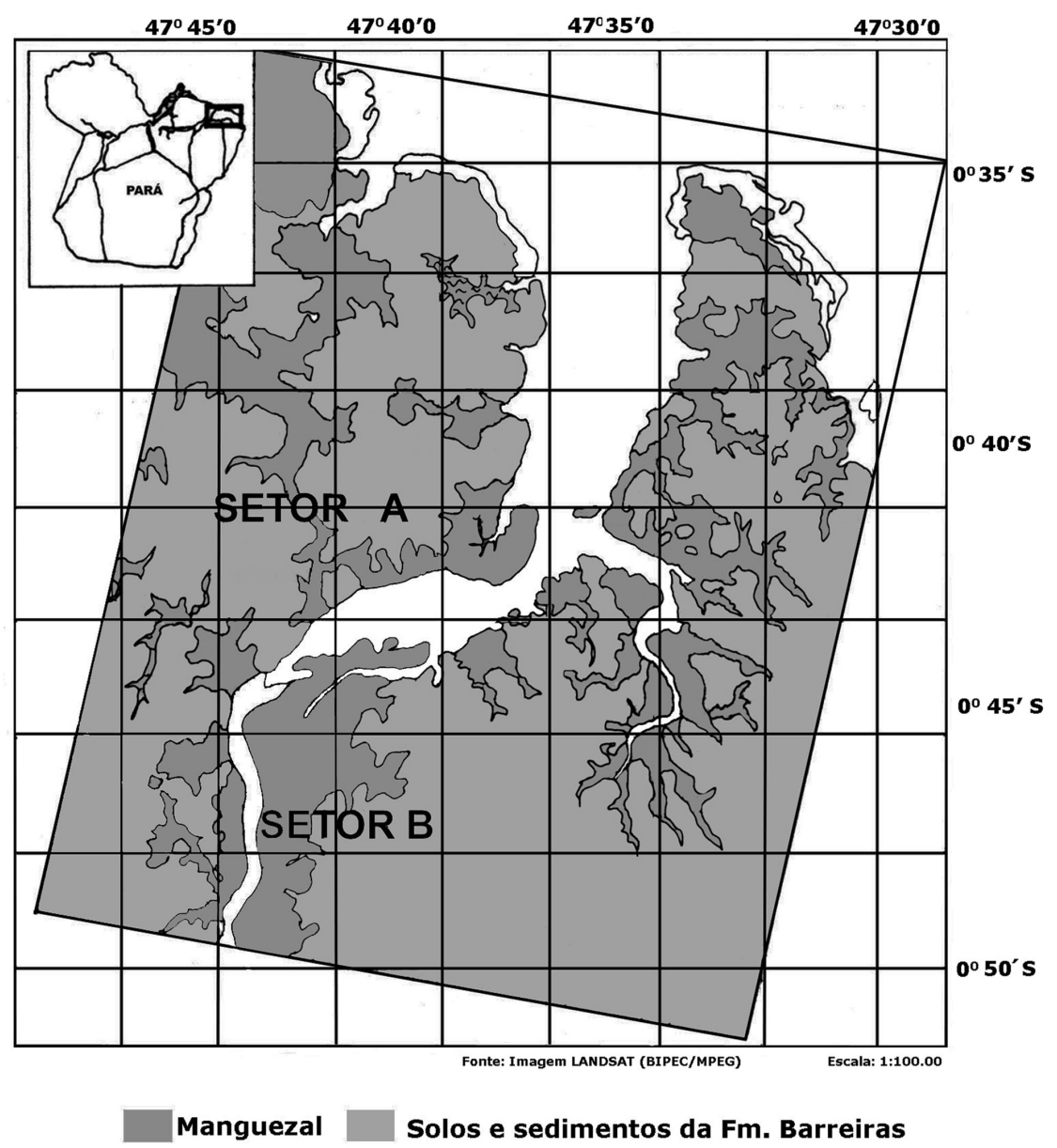

Figura 1 - Mapa de localização.

de um pequeno volume (gotas) de água intersticial. Medidas de $\mathrm{pH}$ e Eh $(\mathrm{mV})$, foram feitas in situ através da inserção direta (nos sedimentos), de eletrodo de vidro $(\mathrm{pH})$ e eletrodo de platina (Eh) de alta precisão (Garrels \& Christ 1965, Baltzer 1982, Marius 1985).

Logo após as medições dos parâmetros físicoquímicos, os testemunhos foram seccionados ao longo do comprimento para a descrição macroscópica (cor com a carta de Munsel, aspectos mineralógicos, textura e estruturas físicas e biogênicas) e, em seguida, realizou-se a sub-amostragem para análises granulométricas e análises mineralógicas, realizadas nos laboratórios do Centro de Geociências da Universidade Federal do Pará e, observações ao MEV, no laboratório do Museu Paraense Emílio Goeldi.

Para a análise granulométrica as amostras foram secas em estufa a $50{ }^{\circ} \mathrm{C}$, pulverizadas em grau de ágata e separadas as frações silte-argila da areia por peneiramento a úmido (peneira de $0,063 \mathrm{~mm}$ ); O silte foi separado da argila por centrifugação a $1000 \mathrm{rpm}$. As análises granulométricas foram realizadas com auxílio do software SYSGRAN 2.4, adotando-se a classificação de Folk \& Ward (1957).

As análises mineralógicas por difração de raios- $X$ foram realizadas através do difratômetro de raios-x Philips, modelo PW 3710, com anodo de cobre $(\mathrm{Cuk \alpha} 1=$
$1,54060 \AA$ ) ajustado a $45 \mathrm{kV}$ e $40 \mathrm{~mA}$. As amostras foram identificadas por difratometria pelo método do pó e em lâminas orientadas através do método "pipette-on-glass" (Thorez 1976), para a caracterização dos argilominerais. Foram preparados três tipos de lâminas: normal, etilenoglicol e sob aquecimento a $550^{\circ} \mathrm{C}$ ( 2 horas). Os registros foram realizados no intervalo de $5^{\circ}$ a $65^{\circ}$, com leituras de $2 \theta$ para as amostras totais pulverizadas e no intervalo $3^{\circ}$ a $36^{\circ}$ para amostras de argilominerais. As identificações dos minerais foram feitas com auxílio do software APD (PHILIPS) e o Minerva, com banco de dados do ICDD International Center for Diffraction Data.

Análises semiquantitativas dos argilominerais foram realizadas com base no método de Gomes (1988), o grau de cristalinidade da caulinita com o método de Hinckley (1963) utilizando o software desenvolvido por Carneiro (2003). A micromorfologia dos minerais e a morfologia de restos biológicos, principalmente carapaças de diatomáceas, foram investigadas com auxílio de um microscópio eletrônico de varredura (MEV): um equipamento LEO $1450 \mathrm{VP}$, com sistema de energia dispersiva (EDS $500 \mathrm{DP}$ ). As amostras foram dispersas com uma gota de água deionizada e fixadas a uma plataforma metálica através de uma fita de carbono EMITEC K550 (3 x $10^{-1}$ bar e $\left.25 \mathrm{~mA}\right)$.

Para o estudo dos minerais pesados foi uti- 
lizada a fração 125-63 $\mu \mathrm{m}$ e o bromofórmio $(\mathrm{CH}-$ $\mathrm{Br}_{3}$ ) como líquido pesado (densidade $2,89 \mathrm{~g} / \mathrm{ml}$ ); os grãos foram quantificados em microscópio petrográfico. A textura e as características morfológicas foram observadas e analisadas com o auxílio do microscópio eletrônico de varredura (MEV).

Análises químicas totais foram realizadas em amostra total para $\mathrm{SiO}_{2}, \mathrm{Al}_{2} \mathrm{O}_{3}, \mathrm{TiO}_{2} \mathrm{Fe}$ total (como $\left.\mathrm{Fe}_{2} \mathrm{O}_{3}\right), \mathrm{P}_{2} \mathrm{O}_{5}, \mathrm{Na}_{2} \mathrm{O}, \mathrm{MgO}, \mathrm{CaO}, \mathrm{K}_{2} \mathrm{O}$ e elementos-traço foram realizadas no laboratório Actlabs Laboratories Ltd (Canadá), além da Perda ao Fogo $\left(1000{ }^{\circ} \mathrm{C}\right)$. As determinações foram feitas por espectrometria de massa com plasma indutivamente acoplado (ICP-MS) pelo método Codes Lithogeochem Standard Package, utilizando os padrões W2 e WHG-1. A determinação dos teores de carbono orgânico (\% de C) foi realizada por via úmida em amostras secas a temperatura ambiente $\left(28^{\circ} \mathrm{C}\right)$, de acordo com Loring \& Rantala (1992), para sedimentos marinhos argilosos. Trata-se de uma adaptação do método de Walkey-Black (1947) que, segundo Gaudette et al. (1974), apresenta excelente concordância com o método de combustão LECO.

\section{RESULTADOS E DISCUSSÃO}

\section{Mineralogia e geoquímica dos sedimentos} SEDIMENTOS DA FORMAÇÃO BARREIRAS E SOLOS DERIVADOS Constituem a principal área-fonte continental para os sedimentos quaternários. Encontramse expostos em forma de falésias, em um relevo colinoso e levemente ondulado, dispostos ao longo do rio Marapanim e canais de marés. Esses sedimentos são constituídos por arenitos argilosos a conglomeráticos, de cor variegada, fortemente intemperizados, sobre os quais se desenvolveram perfis lateríticos transformados em Latossolos Amarelos de composição argilo-arenosa a areno-argilosos, com concreções ferruginosas, amplamente distribuídos na região (Oliveira Júnior et al. 1997).

SEDIMENTOS DE MANGUEZAIS São constituídos por expressiva fração mineral (minerais detríticos e autigênicos) e orgânica, associadas aos processos não simultâneos de sedimentação e instalação da vegetação de mangue. A fase orgânica resulta do acúmulo e da decomposição da vegetação pioneira que coloniza os sedimentos, raízes e restos de vegetação (folhas, troncos e galhos), que se sucedem no terreno de mangue, além de algas (principalmente diatomáceas) e restos de animais, carapaças de caranguejos e pequenas ostras.

Como característica geral, esses sedimentos são bastante homogêneos, quase sem estrutura sedimentar, enriquecidos gradualmente na base por grãos de areia provenientes das barras arenosas que constituem o substrato. A distribuição granulométrica indica teores médios de silte fino (54\%), argila (40\%) e areia (7\%), nos sedimentos do Setor A e, silte médio (59\%), argila $(33 \%)$ e areia (7\%), no setor B, com aumento generalizado dos teores de argila em profundidade.

Os sedimentos também podem ser diferenciados pelas variações na cor da matriz, pela presença de manchas e pela consistência do material. Essas diferenças ge- ralmente se manifestam até $1 \mathrm{~m}$ de profundidade e refletem mudanças nas propriedades físicas e físico-químicas: teor em água (\%), $\mathrm{pH}$, Eh e salinidade intersticial, controladas por processos de evapotranspiração, associados à sazonalidade marcante do clima e ao nível topográfico que os sedimentos se encontram (Berrêdo 2006).

MATÉRIA ORGÂNICA Os teores de carbono orgânico (\% de C) são gradativamente mais elevados em profundidade (C entre 0,75 e 3,5\%), acompanhados do aumento na freqüência do aparecimento de cristais de pirita $\left(\mathrm{FeS}_{2}\right)$. A ocorrência de abundante pirita nos sedimentos, sob condições químicas altamente redutoras $(\mathrm{Eh}=-400 \mathrm{mv})$, realça a existência de lentos movimentos da água intersticial por condições de baixa permeabilidade, as quais favorecem os processos de decomposição da matéria orgânica por bactérias sulfato redutoras (Berrêdo 2006).

As diatomáceas estão presentes em grande quantidade nos sedimentos dos manguezais estudados. Elas representam o grupo de maior expressão dentre as microalgas bentônicas que compõem os sedimentos devido ao constante aporte de águas estuarinas ao ecossistema (Machado inédito). Em um exame preliminar dos sedimentos, Machado (op cit.) identificou 55 táxons, cujos gêneros de maior ocorrência foram: Coscinodiscus (10 spp), Navicula (9 spp), Cyclotella (5 spp) e Pleurosigma (5 spp.). No Setor B foram identificados 37 táxons, cujos gêneros mais freqüentes foram Coscinodiscus ( 9 spp), Cyclotella (4 spp) e Thallassionema (3 spp).

Com a morte dos organismos, as carapaças se quebram ou são dissolvidas quimicamente, enriquecendo os sedimentos em sílica, a qual se junta ao ciclo da sílica nos processos costeiros. Observações ao microscópio eletrônico de varredura (MEV) mostram que as diatomáceas encontram-se em estado de conservação variável, apresentando-se por vezes bem conservadas ou fragmentadas por ataques mecânicos ou, ainda, com sinais de dissolução química.

\section{Assinaturas mineralógicas nos sedimentos dos man-} guezais Os sedimentos e solos (Latossolos) derivados da Formação Barreiras são constituídos principalmente por quartzo, o mineral dominante nas frações areia e silte, argilominerais (caulinita e illita), além de hematita e goethita (Figs. 2 e 3). Existe ampla ocorrência de minerais acessórios, os quais são representados principalmente por zircão, turmalina, estaurolita, cianita, rutilo e anatásio, além de ocorrências esporádicas de sillimanita, andaluzita, granada, topázio, anfibólio e minerais opacos (Nascimento 2002).

Os sedimentos de manguezal são constituídos por idêntica mineralogia principal, além dos minerais acessórios: zircão, turmalina, estaurolita e cianita, os quais representam, em média, $35 \%, 30 \%, 24 \%$ e $9 \%$ respectivamente; ocasionalmente ocorre o rutilo, sillimanita e opacos como a ilmenita e a magnetita. A correspondência existente entre a mineralogia dos sedimentos dos manguezais com a Formação Barreiras, demonstra a importância desta análise para estudos de proveniência na região em apreço, especialmente no 
tocante às assembléias de minerais pesados, sensíveis indicadores da contribuição da área-fonte continental. Nos manguezais também foram identificados minerais neoformados: esmectita, feldspato potássico, pirita, halita, gipso, jarosita, representados em sua maioria no diagrama de raios- $\mathrm{x}$ das figuras $2 \mathrm{~B}$ e $3 \mathrm{~B}$. Esses minerais também foram identificados por Costa et al. (2004) em manguezais da região de Bragança.

O quartzo é o mineral mais comum encontrado nos sedimentos, presente nas frações areia e silte e em fases subcristalinas como a sílica biogênica que constitui a carapaça das diatomáceas nos manguezais. Os grãos de quartzo observados na fração areia por lupa binocular são angulosos a subangulosos (alguns arredondados), leitosos ou com brilho vítreo e fraturas conchoidais, cobertos por películas de óxidos de ferro ou argila. Nos manguezais, em especial, as observações micromorfológicas ao MEV identificaram indícios de dissolução química na superfície dos grãos situados em maiores profundidades, além de feições de sobrecrescimento de cristais euédricos e cristais de quartzo bem formados com característica autóctone.

Os óxi-hidróxidos de ferro, observados em lupa, além de recobrirem os grãos de quartzo são encontrados preenchendo espaços vazios em volta das raízes de Avicennia sp., remobilizados pelos processos de oxiredução responsáveis pela liberação do ferro próximo à superfície dos sedimentos. O ferro provém da oxidação das piritas ou das partículas oxidadas que chegam em suspensão aos manguezais ou, ainda, da degradação de outros minerais como a jarosita e argilominerais.

O feldspato potássico, tido como autigênico nos sedimentos dos manguezais (Costa et al. 2004), foi identificado esporadicamente, com picos de baixa intensidade através da reflexão de $3,2 \AA$ (Fig. 2 B). Outros minerais autigênicos nos manguezais tais como: pirita, halita, gipso e jarosita, encontrados normalmente nesse tipo de ambiente, refletem os processos de oxi-redução da matéria orgânica e a intensidade da evaporação, associado à topografia dos manguezais.

A pirita, por exemplo, foi identificada apenas a partir de $30-40 \mathrm{~cm}$ de profundidade nas regiões mais baixas dos manguezais e a partir de 70-80 cm nas partes mais elevadas. Observações ao MEV, contudo, evidenciam a presença da pirita em reduzidos cristais euédri$\cos (<1 \mu \mathrm{m})$, em forma piramidal ou bipiramidal, isolados, ocorrendo na parte superior dos sedimentos. Em profundidade, os cristais de pirita tornam-se maiores apresentando-se em forma euédrica, isolados, ou formando arranjos framboidais de tamanho variado (máximo de $33 \mu \mathrm{m}$ ) ou, ainda, inclusos em restos de raízes ou em fragmentos de diatomáceas.

A halita e o gipso, semelhante ao que ocorre com a pirita, foram identificados nos difratogramas de raios-x somente em maiores profundidades. $\mathrm{O}$ exame micromorfológico descreve melhor sua presença nos sedimentos a partir de cristais bem formados observados ao MEV: a halita na forma cúbica e o gipso, em forma prismática ou lamelar. Esses minerais ocorrem principalmente em amostras obtidas no período de es-
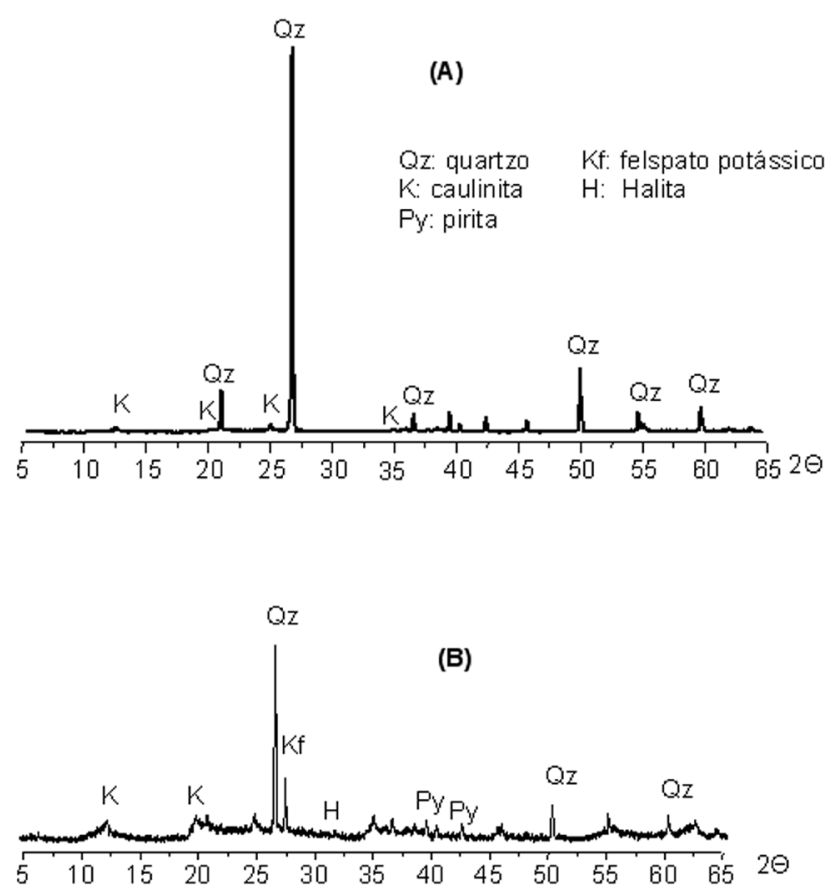

Figura 2 - Difratogramas de raios-X em amostra total: (A) Fm. Barreiras e (B) manguezal.
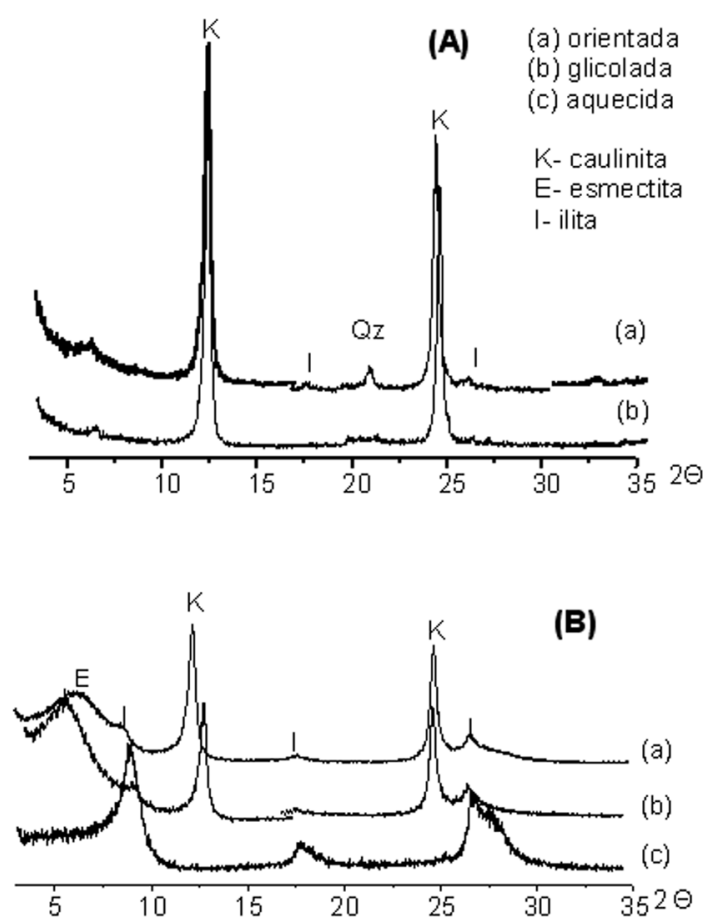

Figura 3 - Difratogramas de raios-X na fração argila: (A) Fm. Barreiras e (B) manguezal.

tiagem, formados na superfície do sedimento pela evaporação de fluidos salinos. 
A jarosita, principal produto da oxidação da pirita, foi identificada apenas por raios-X através das reflexões de maior intensidade: $3,07 \AA$ e $5,0 \AA$. Nos sedimentos do Setor A, a jarosita é freqüentemente detectada nas lâminas orientadas de argilominerais, aparecendo menos facilmente em lâmina de amostra total.

A jarosita aparece com freqüência no setor B, em zonas mais elevadas, intensamente dissecadas, com sedimentos mais permeáveis. Nesses lugares, o pH situa-se entre 3,5 a 4 e os valores de Eh próximos a +400 $\mathrm{mV}$. Essas condições favorecem a formação do mineral, de acordo com os campos de estabilidade estabelecidos no diagrama de Van Breemen (1976), segundo o qual, em solos submersos o aparecimento da jarosita está limitado à condições fortemente ácidas $(1,7<\mathrm{pH}<4)$ e oxidantes $(\mathrm{Eh}>+400 \mathrm{mV})$.

Minerais de argila A análise semi-quantitativa obtida a partir dos difratogramas mostra a predominância da caulinita (70 a 71,4\%), seguido da esmectita (22 a $25 \%$ ) e illita (4 a $5 \%$ ), nesta ordem de ocorrência em cerca de 100 amostras dos setores A e B (Fig. 4). Não existe um padrão comum na distribuição da caulinita e da esmectita em profundidade, apenas da illita, que praticamente não se altera ao longo dos testemunhos. Variações laterais nos percentuais de caulinita e illita entre os setores A e B de amostragem podem refletir mudanças nos processos de deposição (velocidade de deposição), tendo em vista fontes homogêneas para esses constituintes, semelhante ao observado por Gibbs (1977) nos sedimentos do rio Amazonas.

A caulinita, de baixa cristalinidade, foi identificada através das reflexões em 7,1 $\AA$ e $3,57 \AA$, proveniente dos produtos do intemperismo tropical. Amostras dos sedimentos da área-fonte apresentam melhor cristalinidade (em torno de 1) que a caulinita encontrada nos manguezais $(0,5)$, evidenciando a degradação do mineral nesse ambiente (Fig. 3 A,B).

A esmectita, cuja composição (obtida por EDS) varia entre a saponita e a montimorilonita, foi identificada exclusivamente nos sedimentos de manguezal. $\mathrm{O}$ mineral apresenta picos largos e aparência difusa, de baixíssima cristalinidade (Fig. 3 B). Característica comum da distribuição da esmectita nos sedimentos é o leve aumento da cristalinidade em profundidade.

A esmectita e a caulinita apresentam relações inversas de distribuição em profundidade nos sedimentos, sem um padrão definido, conforme exemplificado no diagrama (Fig. 4). Esse constitui mais um indício da formação da esmectita às expensas da dissolução da caulinita. A baixa cristalinidade da caulinita nos sedimentos de manguezal evidencia a sua alteração para a formação da esmectita em contato com abundantes diatomáceas (sílica biogênica), processo descrito por Michalopoulos et al. (2000) para os sedimentos da costa do Amapá, também observado por Costa et al. (2004) e Berrêdo (2006) para os sedimentos de manguezais da costa paraense.

Assinaturas químicas nos sedimentos de manguezal ELEMENTOS MAIORES Os sedimentos e solos da

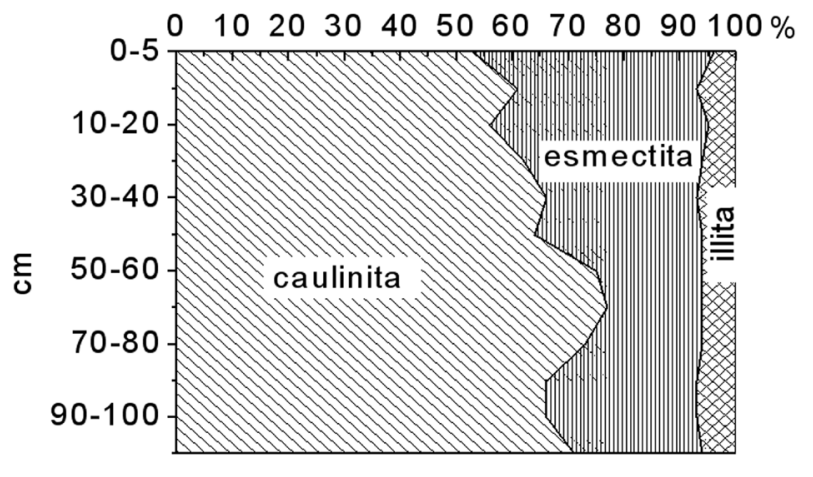

Figura 4 - Distribuição dos minerais de argila nos setores A e B do estuário do rio Marapanim.

Formação Barreiras são ricos em $\mathrm{SiO}_{2} \mathrm{e}_{2} \mathrm{O}_{3}(>85 \%)$ e pobres em $\mathrm{Na}_{2} \mathrm{O}, \mathrm{K}_{2} \mathrm{O}, \mathrm{CaO}$ e $\mathrm{MgO}$ (teores $<1 \%$ ), comparados aos valores crustais (Tab. 1); esses sedimentos são lixiviados pelo intenso intemperismo tropical, semelhante ao comportamento observado em outros solos da Amazônia. Os sedimentos de manguezal são enriquecidos em $\mathrm{SiO}_{2} \mathrm{Al}_{2} \mathrm{O}_{3}$, ferro total (como $\mathrm{Fe}_{2} \mathrm{O}_{3}$ ) e S; $\mathrm{K}_{2} \mathrm{O}, \mathrm{MgO}, \mathrm{Na}_{2} \mathrm{O}, \mathrm{CaO}^{2}$ e $\mathrm{TiO}_{2}$ ocorrem subordinadamente, além de $\mathrm{P}_{2} \mathrm{O}_{5}, \mathrm{MnO}, \mathrm{C}$ e $\mathrm{S}$, comparáveis a outros manguezais da região (Tab. 1).

Nos manguezais os teores de $\mathrm{SiO}_{2}$ situam-se entre 46,58 e $66,7 \%$, com média de $54,45 \%$ e os teores de $\mathrm{Al}_{2} \mathrm{O}_{3}$ entre 12,6 e $21,52 \%$, com média de $18,32 \%$, perfazem juntos mais de $70 \%$ e constituem o quartzo, as carapaças das diatomáceas como sílica amorfa e os minerais de argila. Os teores relativamente elevados de $\mathrm{SiO}_{2} \mathrm{e}_{2} \mathrm{O}_{3}$ e $\mathrm{Fe}_{2} \mathrm{O}_{3}$ demonstram a origem dos sedimentos dos manguezais a partir de sedimentos em avançado grau de intemperismo, como os que compõem a Formação Barreiras e seus produtos de alteração. A composição química é bastante homogênea entre os setores A e B (Fig. 5), observando-se um aumento dos teores de $\mathrm{SiO}_{2}$ em profundidade devido à elevação percentual de quartzo no contato dos sedimentos de manguezal com os sedimentos de barras arenosas sobre as quais os sedimentos lamosos se sobrepõem.

A distribuição dos metais alcalinos varia pouco em profundidade. As concentrações elevadas provêm da água do mar, tendo em vista os baixos teores encontrados na área fonte (Costa et al. 2004). Os teores de $\mathrm{K}_{2} \mathrm{O}$ situam-se em torno de $1,45 \%$ e correspondem aos feldspatos potássicos e/ou esmectitas; os teores de $\mathrm{Na}_{2} \mathrm{O}$ situam-se próximo de $1,43 \%$ e formam principalmente a halita junto com o $\mathrm{Cl}^{-}$. Os teores de $\mathrm{MgO}$ situam-se em torno de $0,89 \%$ e são associados à esmectita com parte do $\mathrm{K}$; o $\mathrm{CaO}$ situa-se em torno de $0,41 \%$ e forma a calcita, embora o mineral não tenha sido identificado com freqüência. Os teores de $\mathrm{Fe}_{2} \mathrm{O}_{3}(6,5 \%)$ e S $(1,6 \%)$ correspondem à formação da pirita e os teores de $\mathrm{TiO}_{2}$ $(0,7 \%)$, provavelmente ao anatásio.

A razão $\mathrm{SiO}_{2} / \mathrm{Al}_{2} \mathrm{O}_{3}$ nos sedimentos de manguezal correlaciona-se aos padrões NASC e PASS, refletindo essencialmente o domínio da caulinita na constituição da- 
Tabela 1 - Composição química média dos sedimentos de manguezais da costa paraense, Formação Barreiras e solos amazônicos.

\begin{tabular}{|c|c|c|c|c|c|c|}
\hline $\begin{array}{l}\text { Elementos } \\
(\mathrm{em} \%)\end{array}$ & $\begin{array}{l}\text { Marapanim } \\
\text { (1) }\end{array}$ & $\begin{array}{l}\text { Bragança } \\
\text { (1) }\end{array}$ & $\begin{array}{c}\text { Formação } \\
\text { Barreiras (2) }\end{array}$ & \multicolumn{2}{|c|}{$\begin{array}{c}\text { Solos da Amazônia } \\
\text { Central (3) }\end{array}$} & $\begin{array}{c}\text { Crosta } \\
\text { Continental (4) }\end{array}$ \\
\hline $\mathrm{SiO}_{2}$ & 54,47 & 55,16 & 66,33 & $70,22^{\mathrm{a}}$ & $52,0^{\mathrm{b}}$ & 66,0 \\
\hline $\mathrm{Al}_{2} \mathrm{O}_{3}$ & 18,32 & 15,18 & 21,68 & 16,66 & 20,0 & 15,2 \\
\hline $\mathrm{MgO}$ & 0,90 & 1,40 & 0,05 & 0,18 & 0,04 & 2,20 \\
\hline $\mathrm{CaO}$ & 0,41 & 0,39 & 0,05 & 0,00 & 0,001 & 4,20 \\
\hline $\mathrm{F}_{2} \mathrm{O}_{3}$ & 6,51 & 5,20 & 1,34 & 2,79 & 15,78 & 4,49 \\
\hline $\mathrm{TiO}_{2}$ & 0,69 & 0,59 & 1,00 & 0,62 & 1,12 & 0,50 \\
\hline $\mathrm{Na}_{2} \mathrm{O}$ & 1,46 & 2,60 & 0,04 & 0,00 & 0,04 & 3,90 \\
\hline $\mathrm{K}_{2} \mathrm{O}$ & 1,47 & 1,38 & 0,07 & 0,04 & 0,10 & 3,40 \\
\hline $\mathrm{P}_{2} \mathrm{O}_{5}$ & $<700 \mathrm{ppm}$ & $<657 \quad$ ppm & - & 0,04 & 0,07 & 0,20 \\
\hline$\% \mathrm{C}$ & 2,59 & - & - & - & - & - \\
\hline $\mathrm{MnO}$ & 0,03 & - & 0,003 & 0,02 & 0,08 & 0,08 \\
\hline $\mathrm{S}$ & 1,57 & 4,95 & - & - & - & - \\
\hline Perda ao fogo & 14,88 & 13,28 & - & - & - & - \\
\hline
\end{tabular}

${ }^{1}$ Manguezais do nordeste do estado do Pará (clima úmido) - Berrêdo (este estudo); Costa et al. (2004);

${ }^{2}$ Formação Barreiras (este estudo);

${ }^{3}$ Kronberg et al. (1979) ${ }^{\mathrm{a}}$; Konhauserb ${ }^{\mathrm{b}}$ et al. (1994);

${ }^{4}$ Taylor \& Mclennan (1985).

queles sedimentos. A razão $\mathrm{SiO}_{2} / \mathrm{Al}_{2} \mathrm{O}_{3}$ mantém-se entre 2 e 3,5 (média de 2,89), mais baixa que NASC $(3,83)$ e PASS $(3,32)$; a média $\mathrm{K}_{2} \mathrm{O} / \mathrm{Na}_{2} \mathrm{O}(1,07)$ é extremamente baixa comparada a NASC $(3,08)$ e PASS $(3,48)$.

Variações na razão $\mathrm{SiO}_{2} / \mathrm{Al}_{2} \mathrm{O}_{3}$ foram detectadas nesses sedimentos, entre os setores $\mathrm{A}$ e $\mathrm{B}$, embora a distribuição média dos argilominerais varie pouco ao longo do grosseiras.

ELEMENTOS-TRAÇO A contribuição do material laterítico e dos solos derivados da Formação Barreiras é evidenciada a partir do enriquecimento dos sedimentos de manguezais em $\mathrm{SiO}_{2}, \mathrm{Al}_{2} \mathrm{O}_{3}$, $\mathrm{Fe}_{2} \mathrm{O}_{3}$ e $\mathrm{TiO}_{2}$. Por outro lado, as baixas concentra-
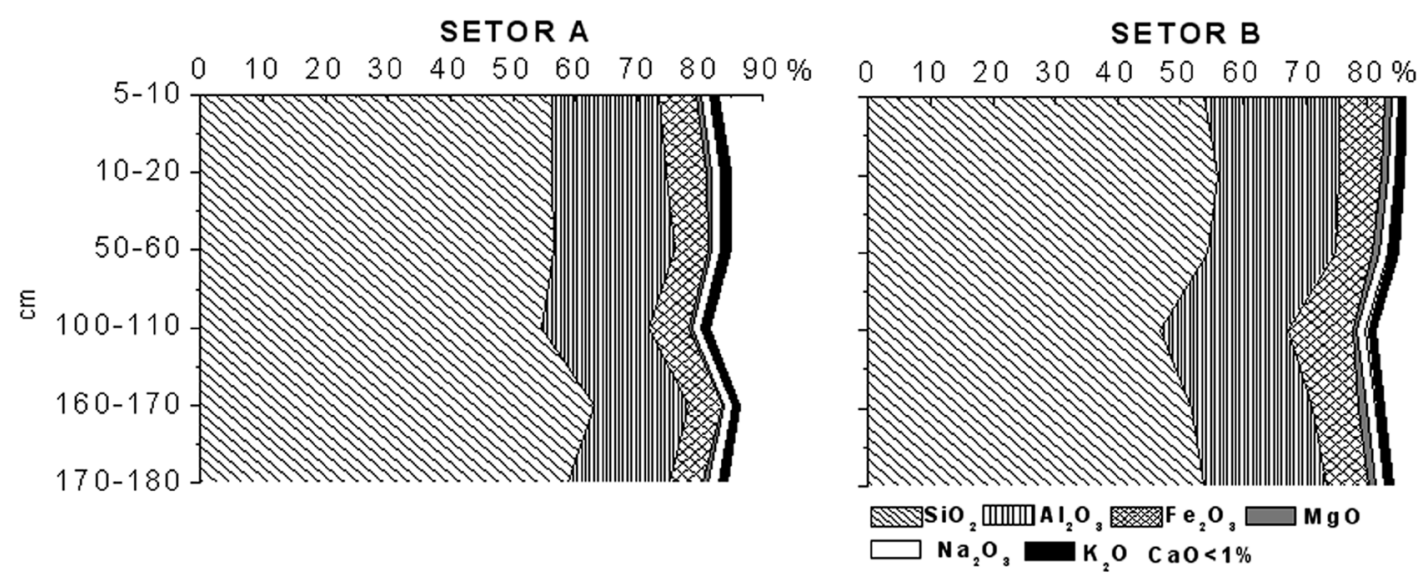

Figura 5 - Distribuição dos elementos químicos maiores entre os setores A e B da área de estudo.

estuário do rio Marapanim. Entre esses setores, $\mathrm{o}$ aumento nos teores de $\mathrm{Al}_{2} \mathrm{O}_{3}(17,5$ para $20 \%)$, no Setor $\mathrm{B}$, induz à diminuição da razão $\mathrm{SiO}_{2} / \mathrm{Al}_{2} \mathrm{O}_{3}(3,21$ para 2,63), atribuído à proximidade dos sedimentos da Formação Barreiras. A influência da área-fonte nessa região é corroborada pelo aumento nos teores de $\mathrm{Fe}_{2} \mathrm{O}_{3}(6,26$ a $7 \%)$ e teores mais elevados $\mathrm{em}^{-\mathrm{TiO}_{2}}$ (em torno de $1 \%$ ), provavelmente associados ao anatásio, mineral característico das frações mais ções dos elementos-traço são próximas aos valores médios da crosta terrestre superior (Tab. 2), não evidenciando influência antrópica; no entanto, essas concentrações são correlacionáveis aos solos lateríticos, altamente lixiviados da Amazônia (Kronberg et al. 1979).

Comparando-se aos valores normalizados da crosta continental superior (Fig. 6), verifica-se 
Tabela 2 - Concentrações (valores médios) de elementos-traço nos sedimentos de manguezais do rio Marapanim comparados com a crosta continental superior, manguezais de Bragança, Formação Barreiras, PAAS e NASC.

\begin{tabular}{l|c|c|c|c|c|c|c|c|c|c|c|c}
\hline Elementos & $\mathrm{Pb}$ & $\mathrm{Mo}$ & $\mathrm{Ga}$ & $\mathrm{As}$ & $\mathrm{Nb}$ & $\mathrm{Hf}$ & $\mathrm{Th}$ & $\mathrm{U}$ & $\mathrm{Sn}$ & $\mathrm{Rb}$ & $\mathrm{Ta}$ & $\mathrm{Cs}$ \\
\hline Marapanim $^{1}$ & 14,3 & 3,3 & 19,6 & 16,8 & 15,6 & 8 & 13,86 & 3,47 & 1,67 & 73,17 & 1,25 & 4,63 \\
\hline Crosta Cont. $^{2}$ & 20 & 1,5 & 17 & 1,5 & 25 & 5,8 & 10,7 & 2,8 & 5,5 & 112 & 2,2 & 3,7 \\
\hline Bragança $^{3}$ & 60,6 & $<3$ & 26,7 & 13,6 & 17,7 & - & - & - & - & - & - & - \\
\hline PAAS & 20 & 1 & 20 & - & 19 & 5 & 14,6 & 3,1 & 4 & 160 & - & 15 \\
\hline NASC & 20 & - & - & 28,4 & 13 & 6,3 & 12,3 & 2,66 & - & 125 & 1,12 & 5,16 \\
\hline
\end{tabular}

\begin{tabular}{l|c|c|c|c|c|c|c|c|c|c|c}
\hline Elementos & $\mathrm{Sr}$ & $\mathrm{Ba}$ & $\mathrm{V}$ & $\mathrm{Zr}$ & $\mathrm{Ni}$ & $\mathrm{Co}$ & $\mathrm{Cr}$ & $\mathrm{Zn}$ & $\mathrm{Cu}$ & $\mathrm{Sc}$ & $\mathrm{Y}$ \\
\hline Marapanim $^{1}$ & 86 & 238,8 & 90 & 322,8 & 22 & 8 & 82 & 66 & 10,7 & 14,7 & 27,7 \\
\hline Crosta Cont. $^{2}$ & 350 & 550 & 60 & 190 & 20 & 10 & 35 & 71 & 25 & 11 & 22 \\
\hline Bragança $^{3}$ & 140 & 248 & 76,8 & 361 & $<14$ & 12,3 & 78 & 52 & $<20$ & - & 32,8 \\
\hline PAAS & 200 & 650 & 150 & 210 & 55 & 23 & 110 & 85 & 50 & 16 & 27 \\
\hline NASC & 142 & 636 & 130 & 200 & 58 & 25,7 & 125 & 2,7 & - & 14,9 & 35 \\
\hline
\end{tabular}

\begin{tabular}{|c|c|c|c|c|c|c|c|c|c|c|c|c|c|c|}
\hline Elementos & $\mathrm{La}$ & $\mathrm{Ce}$ & $\operatorname{Pr}$ & $\mathrm{Nd}$ & $\mathrm{Sm}$ & $\mathrm{Eu}$ & Gd & $\mathrm{Tb}$ & Dy & $\mathrm{Hb}$ & $\mathrm{Er}$ & $\mathrm{Tm}$ & $\mathrm{Yb}$ & $\mathrm{Lu}$ \\
\hline Marapanim ${ }^{1}$ & 50,1 & 86,3 & 9,4 & 36,1 & 7,15 & 1,61 & 5,69 & 0,96 & 5,42 & 1,05 & 3,10 & 0,45 & 3,02 & 0,450 \\
\hline Crosta Continental $^{2}$ & 30 & 64 & 7,1 & 26 & 4,5 & 0,88 & 3,8 & 0,64 & 3,5 & 0,80 & 2,3 & 0,33 & 2,2 & 0,32 \\
\hline Fm. Barreiras Pará ${ }^{3}$ & 225 & 159,71 & 120,7 & 65,5 & 29,6 & 14,1 & 16,5 & 11,9 & 10,1 & 7,4 & 8,55 & 8,1 & 8,4 & 8,2 \\
\hline Fm. BarreirasAmapá ${ }^{4}$ & 173,8 & 98,4 & 71,2 & 47,3 & 27,3 & 14,1 & 15,5 & 13,4 & 12,8 & 9,7 & 12,2 & 13,1 & 12,5 & 12,6 \\
\hline PAAS & 38 & 80 & 8,9 & 32 & 5,6 & 1,1 & 4,7 & 0,77 & 4,4 & 1,0 & 2,9 & 0,4 & 2,8 & 0,43 \\
\hline NASC & 32 & 73 & 7,9 & 33 & 5,7 & 1,24 & 5,2 & 0,85 & 5,8 & 1,04 & 3,4 & 0,50 & 3,1 & 0,48 \\
\hline
\end{tabular}

${ }^{1}$ Manguezais do nordeste do estado do Pará (clima úmido); $\quad{ }^{2}$ Crosta Continental Superior - Taylor \& Mclennan (1985); ${ }^{3}$ Costa et al. (2004); este estudo; ${ }^{4}$ Vital et al. (1999);

PAAS: argilas australianas pós-arqueanas (Taylor \& Mclennan, 1985);

NASC: argilas norte americanas pós-arqueanas (Gromet et al., 1984).

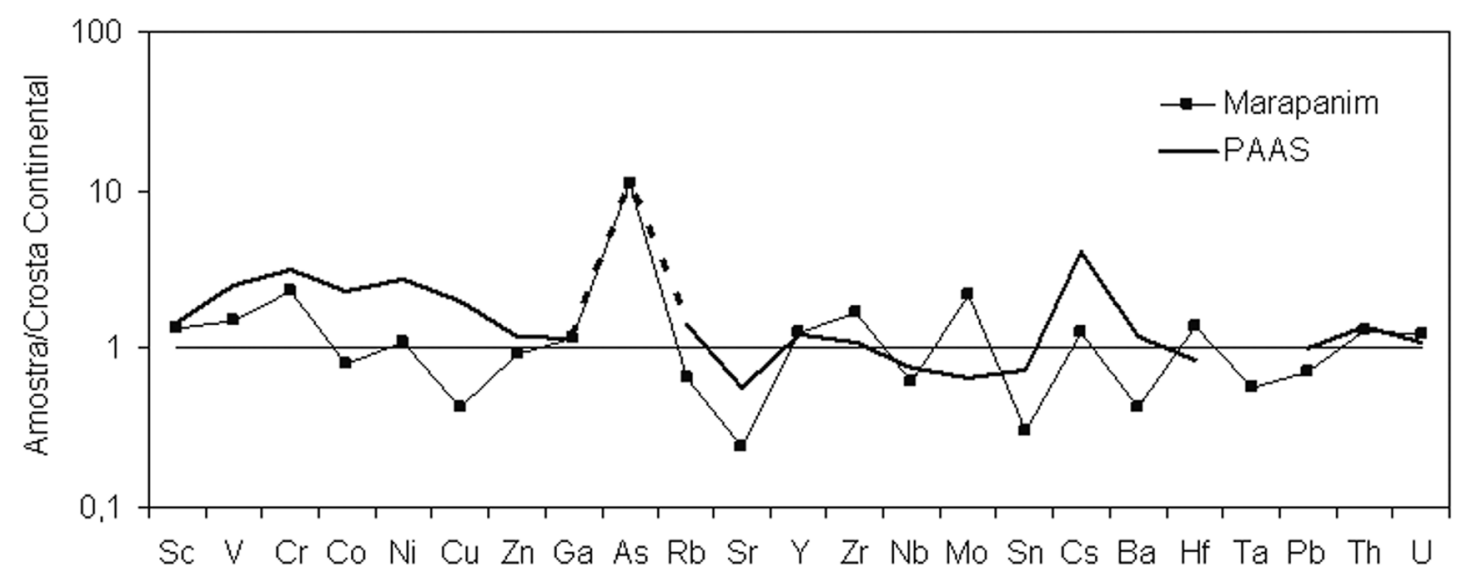

Figura 6 - Concentrações de elementos-traço nos sedimentos de manguezais normalizadas pela crosta continental superior, comparados ao PAAS. 
o enriquecimento dos elementos-traço nos sedimentos de manguezais na seguinte ordem: As, $\mathrm{Cr}, \mathrm{Mo}, \mathrm{Zr}, \mathrm{V}$, Hf, Sc, Th, Y, Cs, U, Ga, Ni. Esses elementos químicos estão presentes na crosta terrestre superior como minerais resistatos, associados à hematita ou goethita ou à matéria orgânica nos solos amazônicos (Kronberg et al. 1979, Costa et al. 2004).

Os elementos-traço são levemente enriquecidos nas zonas superiores dos sedimentos dos manguezais, diminuindo seus teores em profundidade; exceção cabe ao $\mathrm{Zr}$ e Hf, cujos teores aumentam em profundidade indicando a presença do mineral zircão nas frações mais grosseiras. Os teores desses elementos são comparáveis às argilas pós-arqueanas (NASC e PASS), como o As, em relação ao índice NASC (Gromet et al. 1984), provavelmente associado a óxidos de ferro em sedimentos oxidados ou à matéria orgânica; outros elementos como $\mathrm{Sc}, \mathrm{Ga}, \mathrm{Nb}$ e Th, estão situados próximos ou igualandose ao índice PASS (Taylor \& Mclennan 1985).

As associações mineralógicas identificadas nos sedimentos de manguezal são confirmadas através de correlações químicas (coeficiente de correlação $r$, entre parênteses) significativas do $\mathrm{Al}_{2} \mathrm{O}_{3}$ com $\mathrm{MgO}(0,99)$; $\mathrm{Fe}_{2} \mathrm{O}_{3}(0,78) ; \mathrm{K}_{2} \mathrm{O}(0,98)$ e $\mathrm{TiO}_{2}(0,63)$ ou do $\mathrm{Al}_{2} \mathrm{O}_{3}$ com o Sr $(0,98) ; \mathrm{V}(0,98) ; \mathrm{Cr}(0,99) ; \mathrm{Zn}(0,94) ; \mathrm{Sc}(0,82) ; \mathrm{Ga}$ $(1,00)$; Co $(0,81)$; Th $(0,96)$; Sn $(0,86)$; Rb $(0,98)$; Ta $(0,73)$; Cs $(0,98))$, as quais confirmam a presença dos minerais de argila, juntamente com fases de sulfetos e óxi-hidróxidos de $\mathrm{Fe}$. Correlações negativas significativas são apresentadas entre $\mathrm{o} \mathrm{Al}_{2} \mathrm{O}_{3} \operatorname{com} \mathrm{o} \mathrm{Zr}(-0,92)$; Hf $(-0,91)$ e Y $(-0,31)$, correspondendo aos sedimentos mais arenosos, onde o zircão se faz presente através da associação $\mathrm{Zr}-\mathrm{Y}-\mathrm{Hf}$, ressaltando a influência da granulometria sobre as propriedades geoquímicas dos sedimentos lamosos. As correlações de $\mathrm{Al}_{2} \mathrm{O}_{3}$ também são bastante significativas com La $(0,98) ; \mathrm{Ce}(0,99) ; \mathrm{Pr}$ $(0,99) ; \mathrm{Nd}(0,99) ; \mathrm{Sm}(0,97) ; \mathrm{Eu}(1,00) ; \mathrm{Gd}(0,98) ; \mathrm{Tb}$ $(0,88)$ e estes com o $\mathrm{MgO}(0,95) ; \mathrm{K}_{2} \mathrm{O}(0,95) ; \mathrm{Fe}_{2} \mathrm{O}_{3}$ $(0,78)$ e $\mathrm{TiO}_{2}(0,67)$, sugerindo a concentração dos ETR nos argilominerais e minerais pesados.

A análise por agrupamento (Fig. 7), obtida a partir das intercorrelações significativas permite distinguir dois grupos mineralógicos de amostras: o primeiro, coordenado principalmente por $\mathrm{Al}_{2} \mathrm{O}_{3}, \mathrm{MgO}$ e $\mathrm{K}_{2} \mathrm{O}$, é associado fortemente com $\mathrm{Sr}, \mathrm{Cr}, \mathrm{Zn}, \mathrm{Sc}, \mathrm{Ga}, \mathrm{Co}$, Th, $\mathrm{Sn}, \mathrm{Rb}, \mathrm{Ta}$ e Cs, corresponde aos argilominerais, representados principalmente pela esmectita. Sub-grupos também podem ser identificados como, por exemplo, dos elementos $\mathrm{Fe}-\mathrm{Zn}-\mathrm{Cu}-\mathrm{Cr}-\mathrm{V}$, ligados à pirita ou sob a forma de óxidos-hidróxidos ou do $\mathrm{C}-\mathrm{S}$ ligado à matéria orgânica. A associação $\mathrm{SiO}_{2}$-Zr-Hf distingue-se dos demais agrupamentos representando fases mais grosseiras (arenosas), justificando as correlações negativas com o $\mathrm{Al}_{2} \mathrm{O}_{3}$.

Nos manguezais, os teores dos Elementos Terras Raras (ETR) são comparáveis aos valores encontrados nos sedimentos da Formação Barreiras e nas argilas pós-arqueanas. Os teores de ETR, normalizados pelos condritos (Fig. 8), exibem semelhantes e uniformes padrões de fracionamento e a característica anomalia negativa do Eu, sugerindo a origem comum dos sedimentos a partir das rochas da crosta continental superior. Em acréscimo, os Elementos Terras Raras Leves (ETRL) são enriquecidas em relação aos Elementos Terras Raras Pesados (ETRP), similar ao encontrado nos sedimentos lamosos do rio Amazonas (Sholkovitz 1988, Nesbitt et al. 1990), cuja área-fonte é comparada aos sedimentos Barreiras.

As razões $\mathrm{Th} / \mathrm{Co} ; \mathrm{La} / \mathrm{Th} ; \mathrm{La} / \mathrm{Sc} ; \mathrm{La} / \mathrm{Co}$ e $\mathrm{Zr} / \mathrm{Sc}$, fortemente enriquecidas em relação ao PASS e menos enriquecidas $\mathrm{em} \mathrm{Th} / \mathrm{Sc}$ e $\mathrm{Ba} / \mathrm{Co}$, sugerem a assinatura

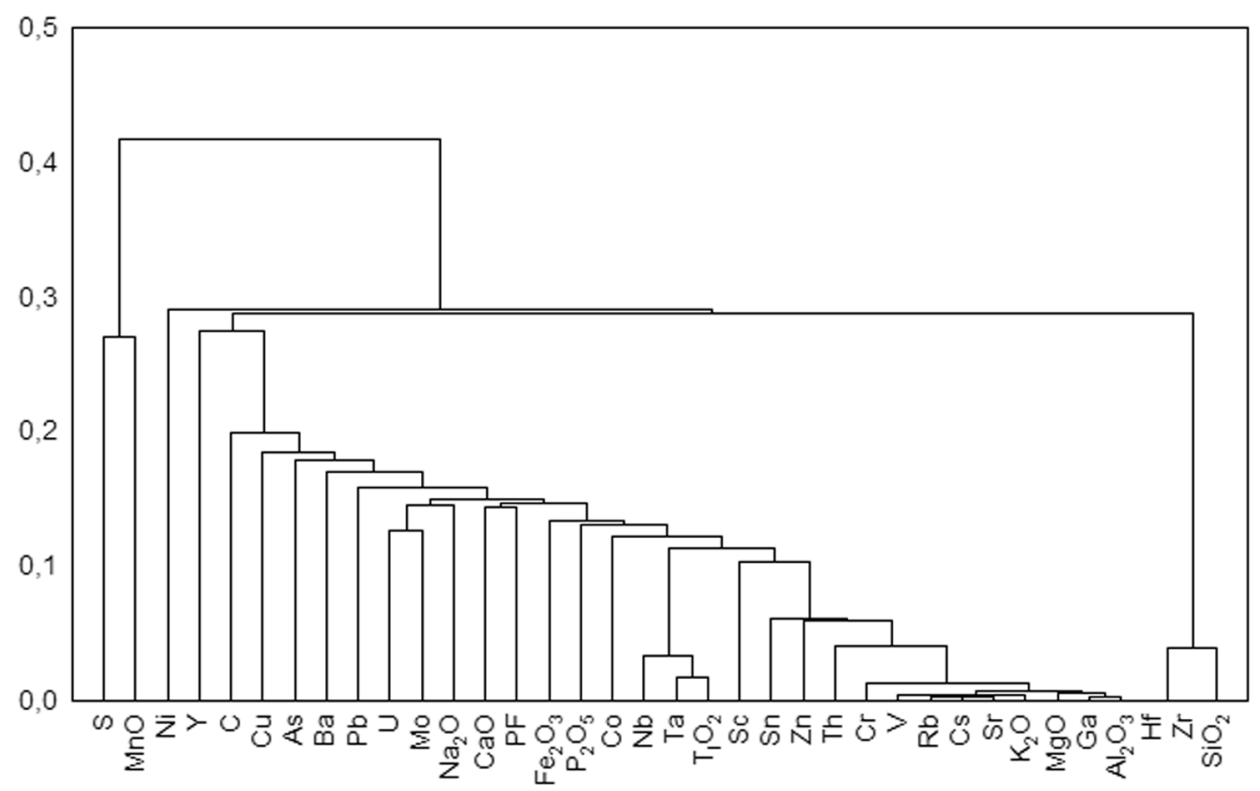

Figura 7 - Análise por agrupamento entre elementos-traço e maiores nos sedimentos de manguezais de Marapanim. 


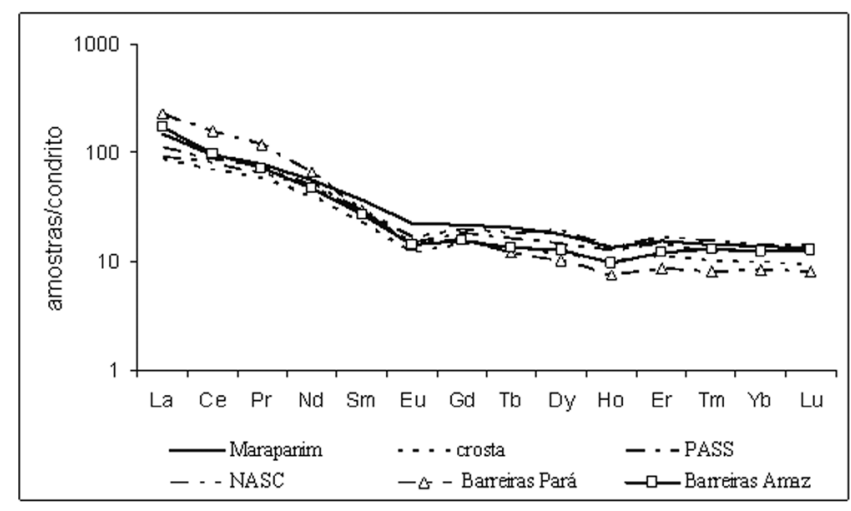

Figura 8 - Conteúdo de Elementos Terras Raras (ETR) nos sedimentos dos manguezais de Marapanim em relação a crosta, Fm. Barreiras (Pará e Amapá), PASS e NASC, normalizados em relação aos condritos.

Tabela 3 - Razões entre elementos-traço nos sedimentos de manguezal comparados ao PASS.

\begin{tabular}{l|c|c}
\hline \multicolumn{1}{c|}{ Elementos } & Marapanim $^{1}$ & PAAS $^{2}$ \\
\hline $\mathrm{Th} / \mathrm{Sc}$ & 0,94 & 0,90 \\
\hline $\mathrm{Th} / \mathrm{Co}$ & 1,73 & 0,60 \\
\hline $\mathrm{La} / \mathrm{Th}$ & 6,26 & 2,60 \\
\hline $\mathrm{La} / \mathrm{Sc}$ & 3,41 & 2,40 \\
\hline $\mathrm{La} / \mathrm{Co}$ & 6,26 & 1,70 \\
\hline $\mathrm{Ba} / \mathrm{Co}$ & 29,85 & 28,30 \\
\hline $\mathrm{Zr} / \mathrm{Sc}$ & 21,96 & 13,1 \\
\hline $\mathrm{La} / \mathrm{Yb}$ & 16,59 & 13,57 \\
\hline$(\mathrm{La} / \mathrm{Yb}) \mathrm{c}$ & 11,18 & 9,17 \\
\hline $\mathrm{La} / \mathrm{Lu}$ & 111,33 & 88,37 \\
\hline$\sum \mathrm{ETR}$ & 210,8 & 183 \\
\hline $\mathrm{ETRL} / \mathrm{ETRP}$ & 8,71 & 9,45 \\
\hline
\end{tabular}

geoquímica de rochas graníticas félsicas nos sedimentos de manguezais de Marapanim (Tab. 3); tais rochas são abundantes em La, Th e Ba, elementos concentrados nos perfis lateríticos pelo intemperismo tropical (Costa 1991). Nesses sedimentos são encontradas altas razões $\mathrm{La} / \mathrm{Yb},(\mathrm{La} / \mathrm{Yb}) \mathrm{c}$ e $\mathrm{La} / \mathrm{Lu}$, relacionadas ao enriquecimento dos ETRL em relação aos ETRP. Por outro lado, a anomalia negativa do Eu é normalmente interpretada como herdada de rochas ígneas félsicas (Cullers \& Graf 1983, McLennan et al. 1980, Taylor \& McLennan 1985, McLennan \& Taylor 1991).

Os solos lateríticos, derivados de rochas graníti- cas, foram identificados por Costa (op. cit.) como parte das fontes dos sedimentos da Formação Barreiras. Contribuições dessas rochas para os manguezais da costa nordeste do Pará são citadas por Costa et al. (2004) e Behling \& Costa (2004). Comparado aos resultados desses autores, os dados apresentados confirmam as importantes contribuições dos sedimentos e solos da Formação Barreiras para a constituição dos sedimentos lamosos do rio Marapanim e para a formação dos depósitos de sedimentos de manguezais da costa paraense.

CONCLUSÕES Os sedimentos que formam a planície estuarina do estuário do rio Marapanim são compostos por expressiva fração mineral (minerais detríticos e neoformados) e fase orgânica, esta última constituída por restos de vegetação, algas (principalmente diatomáceas), animais e pequenos moluscos. Nesses sedimentos ocorre o predomínio da fração silte (54 a 59 \%) sobre a fração argila (33 a $40 \%$ ) a qual aumenta em profundidade, juntamente com a fração areia, próximo ao contato de barras arenosas sobre as quais se sobrepõem; não existem estruturas sedimentares aparentes. Os teores de carbono (\% de C) aumentam em profundidade (máximo de 3,5 $\%$ ), observado frequentemente em zonas mais baixas e constantemente inundadas pelas marés.

Os sedimentos de manguezal estão submetidos a importantes modificações pós-deposicionais observadas próximo da superfície e intensificadas na estiagem, caracterizadas por mudanças na cor, na consistência do material e pelo aparecimento de manchas (aspecto de mosqueamento). Essas variações provocam a diminuição da água intersticial e a alteração físico-química dos sedimentos tornando-os mais ácidos, oxidados e salinizados na estiagem. O processo é acompanhado de intensa remobilização e precipitação de ferro (como óxidos e hidróxidos), de sais de sulfato de cálcio (gipso) e cloreto de sódio (halita), resultado da migração e da supersaturação da água intersticial pela ação da evapotranspiração.

Os sedimentos de manguezal são constituídos principalmente por quartzo, goethita, hematita, caulinita e illita (minerais herdados da área-fonte) e minerais neoformados: esmectita, feldspato potássico, pirita, halita, gipso e jarosita. Basicamente repetem-se as mesmas espécies mineralógicas ao longo da sedimentação estuarina, com algumas mudanças na distribuição em profundidade: o quartzo, de contribuição terrígena, aparece em maior quantidade em direção à base dos sedimentos; os cristais de pirita aumentam de freqüência e tamanho; a halita e o gipso são formados na superfície dos sedimentos por evaporação de fluidos salinos.

A jarosita configura-se como de alteração da pirita, menos presente nos níveis superiores dos sedimentos, mas associada a terrenos altamente oxidados $(\mathrm{Eh}=+$ $400 \mathrm{mV}$ ) e ácidos (pH entre 3,5 a 4). Dentre os argilominerais ocorre o predomínio absoluto da caulinita de baixa cristalinidade, originada pelo intemperismo tropical. A esmectita, de cristalinidade mais baixa que a caulinita e o feldspato potássico, são formados nos manguezais por reações de degradação da caulinita com o significativo conteúdo de diatomáceas presentes nos sedimentos e os 
íons de contribuição marinha.

$\mathrm{O}$ enriquecimento dos sedimentos de manguezais em $\mathrm{SiO}_{2} \mathrm{Al}_{2} \mathrm{O}_{3} \mathrm{Fe}_{2} \mathrm{O}_{3}, \mathrm{TiO}_{2}$ e os baixos teores em metaistraço refletem unicamente a composição mineralógica e química dos sedimentos e solos lateríticos da Formação Barreiras, submetidos ao intemperismo tropical, com teores elevados em $\mathrm{SiO}_{2}$ e $\mathrm{Al}_{2} \mathrm{O}_{3}$ (mais de $70 \%$ ), proporcionado pelo quartzo, caulinita e baixos teores em álcalis $\left(\mathrm{K}_{2} \mathrm{O}, \mathrm{Na}_{2} \mathrm{O}, \mathrm{MgO}, \mathrm{CaO}\right)$. A concentração de $\mathrm{SiO}_{2}$ aumenta em profundidade (associada ao quartzo) e os metais traço concentram-se fracamente na superfície dos sedimentos à exceção do $\mathrm{Zr}$ e Hf, mais concentrados na base do perfil (ligados aos zircões), indicando o aumento de clásticos. A composição química dos sedimentos lamosos é extremamente homogênea $\mathrm{e}$, associada à matéria orgânica, reflete o ambiente de sedimentação e a formação de minerais autigênicos (pirita, esmectita, feldspato potássico, além de gipso, halita e jarosita), caracterizado pela presença de $\mathrm{Fe}$ e S, matéria orgânica $(\% \mathrm{C})$, diatomáceas e pelo aporte de $\mathrm{Cl}^{-} \mathrm{Na}, \mathrm{K}, \mathrm{Ca}$ e $\mathrm{Mg}$ da água do mar.

Os teores e o fracionamento dos elementos-traço assemelham-se aos padrões encontrados nos sedimentos da Formação Barreiras e corroboram a contribuição dessa área-fonte para a constituição dos sedimentos dos manguezais, com o predomínio de ETRL sobre ETRP e elevadas razões de Th/Co; La/Th; La/Sc; $\mathrm{La} / \mathrm{Co}$ e $\mathrm{Zr} / \mathrm{Sc}$ e Th/Sc e Ba/Co, obtidas a partir do intemperismo sobre rochas ígneas félsicas da crosta continental. As associações geoquímicas encontradas nos sedimentos lamosos demonstram a forte influência da área fonte continental através da composição química e mineralógica herdada das litologias da Formação Barreiras, bem como a reorganização dos elementos químicos para a formação de novos minerais, parcialmente em equilíbrio com as condições químicas redutoras e orgânicas existentes nos manguezais. As conclusões apresentadas não ignoram, contudo, a influência de outras fontes como, por exemplo, a influência de sedimentos plataformais, fora do alcance da presente pesquisa.

Agradecimentos Ao CNPq pelo apoio financeiro através dos projetos SelenMerAs (Processo 476.874/2001-7) e Geosedintama (Processo 471109/03-7). Ao CNPq pela concessão de bolsa de produtividade de pesquisa e auxílio pesquisa (Grant) ao segundo autor. Ao Museu Emilio Goeldi (MPEG) pela utilização dos laboratórios de análises químicas.

\section{Referências}

Baltzer F. 1982. La sedimentation et la diagenèse précoce sur les côtes à mangroves. Cah. ORSTOM, Géol., 12:175189.

Barbosa G.V., Pinto M.N. 1973. Geomorfologia da Folha SA-23 (São Luiz) e parte da Folha SA-24 (Fortaleza). In: Brasil (ed.) Projeto Radam Brasil. Folha SA-23 São Luis e parte da Folha SA-24 Fortaleza; geologia, geomorfologia, solos, vegetação e uso potencial da Terra. Rio de Janeiro, Levantamento de Recursos Naturais, 3, Cap.1, p.3-37.

Behling H., Costa M.L. 2004. Mineralogy, geochemistry, and palynology of modern and late Tertiary mangrove deposits in the Barreiras formation of Mosqueiro Island, northeastern Para state, eastern Amazonia. Journal of South American Earth Sciences, 17:285-295.

Berrêdo J. F. 2006. Geoquímica dos sedimentos de manguezais do nordeste do estado do Pará: o exemplo do estuário do rio Marapanim. Tese de Doutoramento, Centro de Geociências, Universidade Federal do Pará, 185 p.

Borges M.S., Costa J.B.S., Bemerguy R.L., Fernandes J.M.G., Costa M.L., Hasui Y. 1995. Evolução neotectônica da região nordeste do Estado do Pará. In: SBG, Simpósio Nacional de Estudos Tectônicos, 5, Resumos, p. 421-422.

Borrego J., López-Gonzáles N., Carro B., Lozano-Soria O. 2005. Geochemistry of rare-earth elments in Holocene sediments of an acidic estuary: Environmental markers (Tinto River Estuary, South-Western Spain). Journal of Geochemical Exploration, 86:119-129.

Carneiro B.S. 2003. O caulim duro da região do Rio Capim, Pará-Mineralogia, geoquímica e avaliação das propriedades cerâmicas. Dissertação de Mestrado, Centro de Geociências, Universidade Federal do Pará, 85 p.
Costa M.L. 1991. Aspectos geológicos dos lateritos da Amazônia. Revista Brasileira de Geociências, 21(2):146-160.

Costa M.L., Behling H., Berrêdo J.F., Siqueira N.V.M. 2004. Mineralogical, Geochemical and Palynological Studies of Late Holocene Mangrove Sediments from Northeastern Para State, Brazil. Revista Brasileira de Geociências, 34(4):479-488.

Cullers R.L. \& Graf J. 1983. Rare earth elements in igneous rocks of the continental crust: intermediate and silicic rocks, ore petrogenesis. In: Henerson P. (ed.) Rare-Earth Geochemistry, Elsevier, p.275-297.

Cullers R.L. 1994. The chemical signature of source rocks in size fractions of Holocene stream sediment derived from metamorphic rocks in the wet montais region, Colorado, USA. Chemical Geology, 111:327-343.

Cullers R.L. 1995. The controls on the major and trace-element evolution of shales, siltstones and sandstones of Ordovician to Tertiary age in wet mountains region, Colorado, USA. Chemical Geology, 123:107-131.

Djuwansah M. 1990. Mangroves de la zone equatorial. Etude sedimentologique, mineralogique et geochimique. Docteur de Specialite, U.F.R des Sciences de la Vie et de la Terre Institut de Geologie, Universite Louis Pasteur, 124 p.

Folk R.L. \& Ward W.C. 1957. Brazos river bar: A study in the significance of grain size parameters. Journal of Sedimentar Petrology, 27:3-27.

Garrels R.M. \& Christ C.L. 1965. Solutions, Minerals and Equilibria. New York, Harper et Row, 450 p.

Gaudette H.E., Flight W.R., Toner L., Folger D.W. 1974. An inexpensive titration method for the determination of organic carbon in recent sediments. Journal Sedimentar Petrology, 44:249-253. 
Gibbs R.J. 1977. Clay mineral segregation in the marine environment. Journal of Sedimentary Petrology, 47:237-243.

Góes Filho L., Veloso H.P., Japiassu A.M.S., Leite P.F. 1973. Vegetação. In: BRASIL (ed.) Projeto RADAM. Folha SA23 (Folha São Luis) e parte da Folha SA-24 (Folha Fortaleza). MME/DNPM, v.3, p.71-72.

Gomes C.F. 1988. Argilas. O que são e para que servem. Lisboa, Fundação Calouste Gulbenkian, 457 p.

Gromet L.P., Dymek R.F., Haskin L.A., Randy L.K.1984. The "North american shale composite": Its compilation, major and trace element characteristics. Geochimica et Cosmochimica Acta, 48:2469-2482.

Hinckley D.N. 1963. Variability in "cristalinity" values among the kaolin deposits of the coastal plain of Georgia and South Carolina. Clays and Clay Minerals, 11:229-235.

Kalck Y. 1978. Evolution des zones a mangroves du Senegal au quaternaire recent, etudes geologiques et geochimiques. Strasbourg. Docteur de Specialite, U.F.R des sciences de la vie et de la terre- Institut de Geologie, Universite Louis Pasteur, $122 \mathrm{p}$.

Kjerfve B., Lacerda L.D. 1993. Mangroves of Brazil. In: Lacerda L.D. (ed.). Conservation and sustainable utilization of mangrove forests in Latin America and Africa Regions. International society for mangrove ecosystems, p 245272 (Tecnical reports., 2).

Konhauser K.O., Fyfe W.S., Kronberg B.I. 1994. Multi-element chemistry of some Amazonian waters and soils. Chemical Geology, 111:155-175.

Kronberg B.I., Fyfe W.S., Leonardos O.H. Jr., Santos A.M. 1979. The chemistry of some brazilian soils: element mobility during intense weathering. Chemical Geology, 24:211-229.

Kronberg B.I., Melfi A.J. 1987. The geochemical evolution of lateritic terranes. Z Geomorph. N.F., Suppl.-Bd, 64:25-32.

Loring D.H. \& Rantala R.T.T. 1992. Manual for the geochemical analyses of marine sediments and suspended particulate matter. Earth-Science e Reviews. 32:235-283.

Marius C. 1985. Mangroves du Sénégal et de Gambie. Paris, ORSTOM, Collection Traveaux et Document ORSTOM 193, 357p.

Martin J.M., Hogdahl O., Philippot J.C. 1976. Rare earth element supply to the ocean. Journal Geophysical Resources, 81:3119-3124.

Mclennan S.M., Nance W.B. Taylor S.R. 1980. Rare earth element-thorium correlations in sedimentary rocks, and the composition of the continental crust. Geochimica et Cosmochimica Acta, 44:1833-1839.

Mclennan S.M. \& Taylor S.R. 1991. Sedimentary rocks and crustal evolution: tectonic setting and secular trends. Journal Geology, 99:1-21.

Michalopoulos P. \& Aller R.C. 1995. Rapid clay mineral for- mation in Amazon Delta sediments: Reverse Weathring and oceanic elemental cycles. Science, 270:614-617.

Michalopoulos P., Aller R.C., Reeder R.J. 2000. Conversion of diatoms to clays during early diagenesis in tropical, continental shelf muds. Geology. 28(12):1095- 1098.

Nascimento M.S. 2002. Minerais Pesados das Formações Ipixuna e Barreiras, região de Ipixuna, leste da sub-bacia de Cametá - NE do Pará. Belém, Dissertação de Mestrado, Centro de Geociências, Universidade Federal do Pará, 86p.

Nesbitt H.W., MacRae N.D., Kronberg B.I. 1990. Amazon deep-sea fan muds: light REE enriched products of extreme chemical weathering. Earth and Planetary Science Letters. 100:118-123.

Oliveira Júnior R.C. de, Silva J.M.L. da, Capeche C.L., Rodrigues T.E. 1997. Levantamento de Reconhecimento de Alta Intensidade dos Solos da Folha Marapanim, Estado do Pará. Belém, Boletim de pesquisa, 180, 53p.

Prost M.T., Bastos M.N., Furtado L.G., Gorayeb I., Mendes A .C., Berrêdo J., F. Faure J.F., Sales M.E., Silva C.A., Luz L.M. 2001. Manguezais paraenses: subsídios para o desenvolvimento sustentável. In: Reunião especial da SBPC, 7, Manaus, Atas, CD- Rom.

Schaeffer-Novelli Y. 1986. Manguezais Brasileiros: uma bibliografia (1614-1986). São Paulo, Instituto Oceanográfico, Universidade de São Paulo, 59p.

Sholkovitz E.R. 1988. Rare earth elements in the sediments of the north Atlantic Ocean, Amazon Delta, and East China Sea: reinterpretation of terrigenous input patterns the oceans, Am. J. Sci., 288:236-281.

Silva C.A. da. 1998. Análise morfoestratigráfica do estuário do rio Marapanim-NE do Pará. Dissertação de Mestrado, Centro de Geociências, Universidade Federal do Pará, 133 p.

Taylor S.R. \& Mclennan S.H. 1985. The continental crust: Its composition and evolution. Oxford, Blackwell, 312p.

Thorez J. 1976. Practical identification of clay minerals. Bélgique, G. Lelotte, 90 p.

Van Breemer N. 1976. Genesis and solution chemistry of acid sulfate soils in Thailand. Wageningen, Pudoc, Centre for Agricultural Publishing and Documentation, 263p.

Walkey-Black A. 1947. A critical examination of a rapid method for determining organic carbon in soil. Soil Science, 63:251-263.

Yang S.Y, Jung H.S., Choi M.S, Li C.X. 2002. The rare earth element compositions of the Changjiang (Yangtze) and Huanghe (Yellow) river sediments. Earth and Planetary Science Letters, 201:407-419.

Manuscrito ID 7668

Submetido em 24 de março de 2007 Aceito em 31 de dezembro de 2007 Sistema eletrônico de submissão 